\title{
Numerical interpretation of pressurized corroded cast iron pipe tests
}

Chunshun Zhang, Suranji Rathnayaka, Benjamin Shannon, Jian Ji ${ }^{*}$, Jayantha Kodikara

Department of Civil Engineering, Monash University, Clayton, VIC, 3800, Australia

\begin{abstract}
Pitting/patch corrosion is a major and common cause of leaks and (or) bursts in cast iron (CI) pipes that consist of over $50 \%$ of global pipelines. The determination of the remaining life of a CI pipe is a major challenge facing water utilities requiring an estimate of the impact of pitting corrosion on the degradation of structural pipe capacity. This paper uses an efficient finite element analysis (FEA) to model the behaviour of large diameter CI pipes with natural or simulated corrosion pits and patches. The test results were obtained through laboratory pressure testing. Laser scanning was used to develop three dimensional geometric models of pipe specimens for direct use in the numerical modelling. The CI material was simulated by a non-linear hyperbolic elastic model (termed MHM-CI) recently developed by the authors for CI pipe modelling. The numerical results showed that the proposed FEAs with the MHM-CI model are reasonably capable to predict the measured responses with increasing water pressure, importantly at the critical pipe corrosion patches, such as hoop strains, initiation of leak and burst failures. The initiation of fracture was explained by material failure purely by tension, which can form a crack that could lead to water leakage. Final burst possibility was modelled by using a simplified fracture mechanics approach to determine the critical crack length for spontaneous fast fracture as in a burst. Our numerical findings suggest that the proposed simplified numerical approach may be used to determine whether a corroded cast iron pipe would leak before break provided that the corrosion condition of the pipe and the relevant material properties are available. However, the window of time for leak before break would require further testing since this would be governed by sub critical fracture growth subject to repetitive external and internal pipe loadings.
\end{abstract}


Keywords: cast iron pipe; hyperbolic nonlinear elastic model; FEA; leak before break, pipe burst testing, corrosion pitting

\section{Introduction}

Cast iron (CI) pipes had been widely installed until the 1970s as main components of underground networks in most cities around the world. As a result, over $50 \%$ of the current global water pipe assets are cast iron pipelines. A large number of buried CI pipes are still in service, transporting water, gas and sewage in most urban centres. Such a long-term exposure of the pressurized pipes to various complicated in-situ environmental (soil, water, biological and chemical) conditions causes the formation of various pipe defects, e.g., pitting corrosion. Depending on the severity of the corrosion pits, the structural capacity of a CI pipe could be significantly reduced, leading to pipe leaks and bursts, causing significant incidents. The failure of large diameter critical water mains could lead to significant consequences involving economic, societal and environmental damages. Therefore a thorough understanding of failure mechanics of corroded buried pipes and more improved failure prediction tools are necessary to advance the proactive pipe asset management.

Pipe burst testing is a useful technique to study the remaining structural capacity of aged CI pipes with considerable corrosion. Despite this, there has not been any pressurized burst test for corroded large diameter (over 300mm) CI pipes reported in literature. The only relevant pipe burst tests which the authors could find were conducted by Schlick [1], but Schlick's tests were targeted at testing the structural capacity of pristine pipes as needed at the time for new pipe design, in contrast to deteriorated buried CI water pipes.

As part of the Critical Pipe Project, three critical (indicating large pipe diameter over 300 $\mathrm{mm})$ pressurized corroded CI pipe burst tests were conducted and analysed in the newly developed burst test facility at the Monash Civil Engineering laboratory [2-4]. They were intended to examine size and depth of a corrosion patch that is required to cause a leak and burst under likely operating (water) pressures. One of the major findings is that contrary to previous belief of sudden bursts of brittle cast iron pipes, buried pipes are likely to leak first before ending up as a burst, or in other words, the leak before break (LBB) concept may also 
be applicable to buried cast iron water pipes. It is also found that the patch needs to be a sufficiently large and maximum corrosion in the patches needs to be approximately more than $80 \%$ of the original wall thickness in order for a leak to develop at typical operational water pressures [4].

Theoretical analysis, if validated, can also be used cost-effectively to estimate the remaining structural capacity of a corroded CI pipe. Theoretical analysis can be carried out using a number of approaches, which can be generally grouped into two categories. The first category is to develop some simple analytical methods based on fundamental structural mechanics. In analytical methods, a pipe is generally simplified to be a ring section with a (or reduced) uniform thickness when accounting for the material loss due to general corrosion [5-7]. The other category is to carry out numerical modelling for a full-scale pipe, mostly, via FEA that accounts for individual corrosion patches or pits. FEA has been widely used to study various pipe problems, enabling to include various load and boundary conditions acting on the pipe, and also the interaction between pipe and surrounding soil [8-12]. For example, [8] investigated pipe-soil interaction for pipes buried in expansive soil when subjected to swelling soil movement due to increase in moisture content, and [10] conducted 3-D FEAs to model ring bearing and pipe bending tests where the CI nonlinearity was modelled using multilinear elastic material behaviour. As can be seen in these papers, although the effect of the external loads on the mechanical behaviour of CI pipes was demonstrated, little attention has been paid to the impact of internal water pressure that causes a pipe to leak and burst.

The present paper presents a set of FEAs of burst tests of pressurised corroded CI pipes, conducted at Monash University. The FEAs identify the actual and artificial pipe corrosions via high-resolution laser-scanning of the corroded pipe external and internal surfaces. The nonlinearity of the CI material is characterised by a hyperbolic nonlinear elastic model (e.g., MHM-CI) that has been recently implemented in FEA by the authors. A priority of the numerical analyses is to accurately predict the leak and burst pressures of the corroded CI 
pipes. Additionally, the predicted hoop strains at the artificial corrosion patches are found to be reasonably close to the experimental counterparts.

The remaining sections of this paper are organized as follows. Section 2 briefly introduces the essential details of the hyperbolic nonlinear elastic model to characterize the CI material nonlinearity. In Section 3, general information about the three testing pipe specimen and their relevant mechanical properties for hyperbolic nonlinear elastic model are introduced. This is followed a detailed presentation of numerical modelling of each pressurized pipe testing in Section 4, where the modelling procedure and numerical results of strains and leak and burst pressures are compared with the experimental measurements. Some final remarks are provided in the final section.

\section{Brief review of hyperbolic nonlinear elastic model: MHM-CI}

Uniaxial tensile and compressive tests of cast iron (CI) material usually show a markedly non-linear stress-strain diagram (due to graphite flake slippage, etc.), which can be most suitably represented by a hyperbolic function $[13,14]$, as shown as follows:

$\sigma=\frac{\varepsilon}{\alpha+\beta \varepsilon}$

where the nonlinear relationship between uniaxial stress, $\sigma$, and uniaxial stress, $\varepsilon$, are related by two parameters, $\alpha$ and $\beta$ calibrated from uniaxial tensile and compressive tests. This hyperbolic function indicates that the elastic (tensile and compressive) moduli are varied, depending on the (tensile and compressive) stresses acting on the test material, as given by Equation (2):

$$
E=\frac{d \sigma}{d \varepsilon}=\frac{1}{\alpha}(1-\beta \sigma)^{2}
$$


Assume the nonlinearity of CI material can be simply described by a simple isotropic nonlinear elastic model, where the stress-dependent modulus takes the form of Eq. (2) with the maximum tensile or compressive stresses, $\sigma_{\max }^{t}$ or $\sigma_{\text {max }}^{c}$ :

$$
\begin{aligned}
& E_{t}=\frac{1}{\alpha_{t}}\left(1-\beta_{t} \sigma_{\text {max }}^{t}\right)^{2} \\
& E_{c}=\frac{1}{\alpha_{c}}\left(1-\beta_{c} \sigma_{\text {max }}^{c}\right)^{2}
\end{aligned}
$$

where, subscripts $c$ and $t$ refer to compressive and tensile stress states.

The stress-dependent elasticity matrix $D_{i j k l}$ is then formulated as per the generalised Hooke's law:

$$
D_{i j k l}=\frac{E_{t} \text { or } E_{c}}{(1+v)(1-2 v)}\left[\begin{array}{cccccc}
1-v & v & v & 0 & 0 & 0 \\
v & 1-v & v & 0 & 0 & 0 \\
v & v & 1-v & 0 & 0 & 0 \\
0 & 0 & 0 & (1-2 v) / 2 & 0 & 0 \\
0 & 0 & 0 & 0 & (1-2 v) / 2 & 0 \\
0 & 0 & 0 & 0 & 0 & (1-2 v) / 2
\end{array}\right]
$$

$D_{i j k l}$ is used to update the incremental stress:

$$
d \sigma_{i j}=D_{i j k l} d \varepsilon_{k l}
$$

Tensile stress increases with the increasing water pressure till the tensile strength of the CI material is reached, resulting in pipe failure. For a detailed derivation and numerical implementation process, the readers can refer to our recent work in [15]

It should be noted that our numerical implementation does not cater for fracture evolution specifically. Instead, when an element has failed, it is deactivated by multiplying its stiffness 
matrix $D_{i j k l}$ by a small reduction factor, to essentially eliminate its contribution to the global structural stiffness. This is a common approach adopted by the existing commercial software packages, such as ANSYS, ABAQUS, ADINA, etc.

A similar hyperbolic nonlinear elastic model has previously been used by [6], where, an analytical solution has been used with simple bending theory, thereby presenting limitations to specific applications. In contrast, we implemented a more general 3-D form of the model in general purpose ABAQUS finite element package so that it could be used in general applications involving external and internal corrosion on large diameter CI pipes, as elaborated in the following Sections.

\section{General information of tested pipe specimen}

\subsection{General pipe information}

Figures $1 \mathrm{a}, 1 \mathrm{~b}$, and $1 \mathrm{c}$ respectively show three burst tests undertaken for the pipes 1, 2 and 3. All of these pipes were cut out from a decommissioned CI pipeline from Strathfield, Sydney. The pipes were cut at the two ends perpendicular to the axis (using water jet cutting), cement lining was removed and the internal and external surfaces were grit-blasted to remove the graphitisation. Three dimensional geometrical reconstruction of these pipe specimens were carried out using a laser scanner as shown in Figures 1d, 1e, and 1f. The pipe burst tests were intended to examine the required size and depth of a corroded patch subject to water pressures at operational levels to cause a pipe leak and burst. However, the collected pipe specimens may resist water pressure above an operating level, as the in-situ pitting corrosion may not be sufficiently progressed. Therefore, as shown in Figures 1 (a) to 1 (c), large and deep corroded patches estimated based on preliminary modelling was artificially created for each pipe specimen so that the patch would leak and burst under an operating pressure. Information of these artificially machined corroded patches and the studied pipes is summarised in Table 1. Corresponding to each pipe specimen for burst testing, the actual profiles of the pipe surfaces were accurately mapped in the numerical models using laser scanned data, as shown in Figures 1(d) to 1(f). As can be seen, the machined corrosion 
patches on each pipe and extensive small natural corrosion pits are clearly presented based on the current scanning resolution of around $1 \mathrm{~mm}$ by $1 \mathrm{~mm}$. it is considered that this level of resolution is sufficient to capture topological features for structural analysis purposes. It should be noted that non-destructive methods (such as magnetic flux leakage or broad band electromagnetics, BEM) normally employed to measure the level of corrosion in pipelines provides much less resolution (in the order of $50 \mathrm{~mm}$ for BEM). Since our focus is on major corrosion patches that may lead to a pipe burst, this level of resolution is more than adequate for structural analysis, and this is specially so for machined patches used in the tests reported in the current paper. The reasonably good comparisons as shown in Figure 6 indicate the suitability of relying on the scanning resolution.

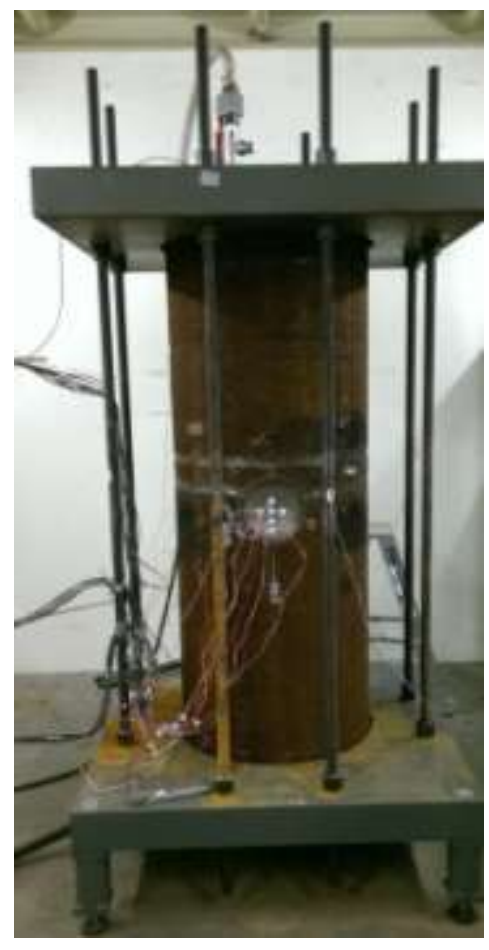

(a) Pipe burst test 1

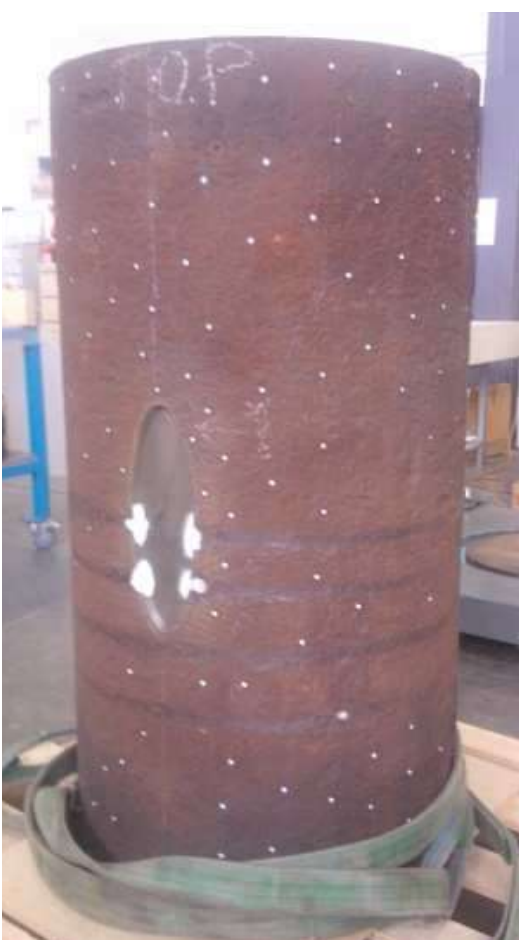

(b) Pipe burst test 2

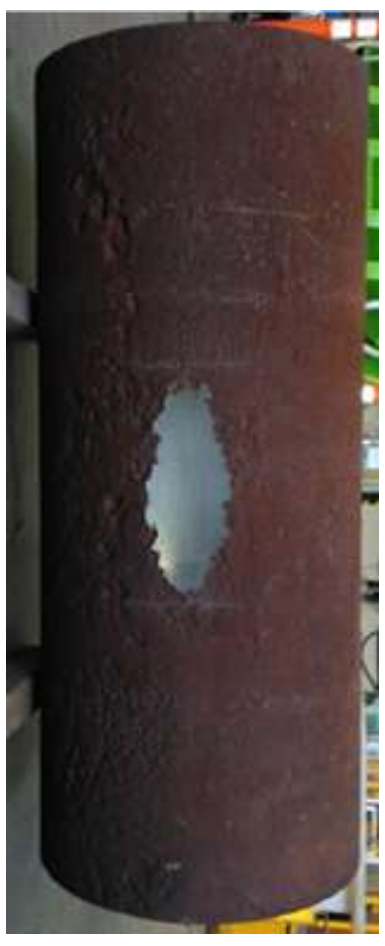

(c) Pipe burst test 3 


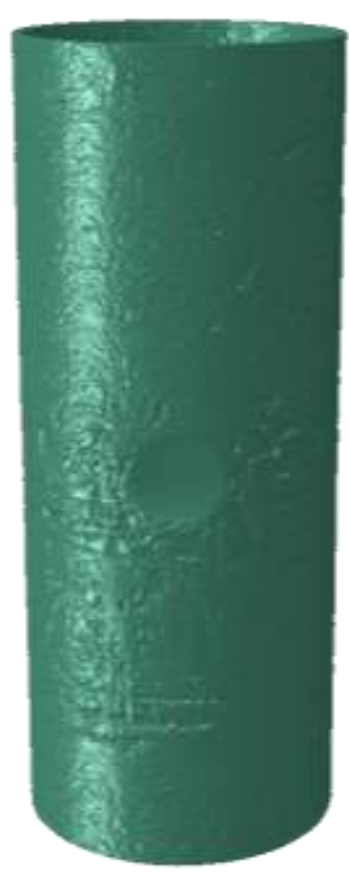

(d) Scanned pipe 1

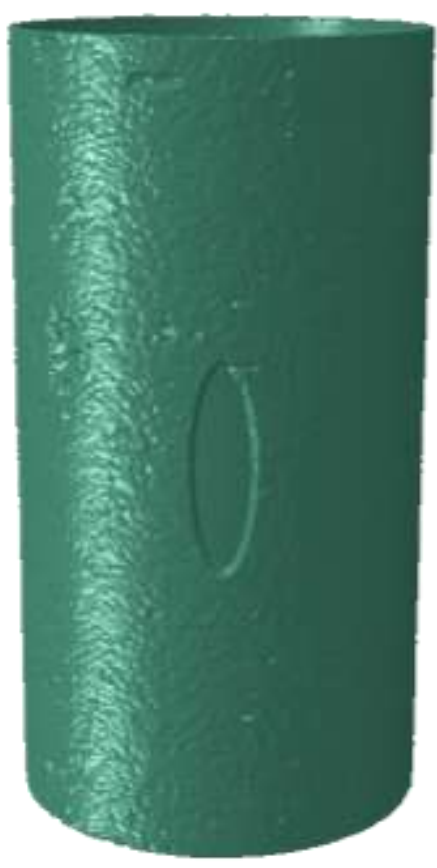

(e) Scanned pipe 2

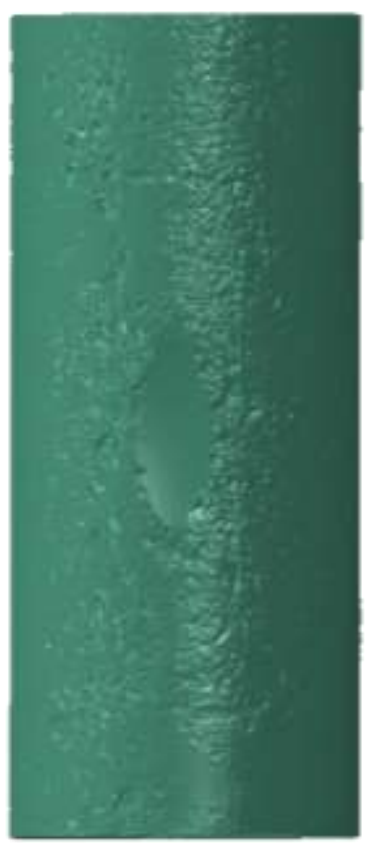

(f) Scanned pipe 3

Figure 1. Tested CI pipes including machined corrosion patches

Table 1 Information of modelled pipes

\begin{tabular}{|l|c|c|c|}
\hline & Pipe burst test 1 & Pipe burst test 2 & Pipe burst test 3 \\
\hline Pipe diameter & \multicolumn{3}{|c|}{$\sim 660 \mathrm{~mm}$} \\
\hline Original wall thinness & \multicolumn{3}{|c|}{$\sim 25 \mathrm{~mm}$} \\
\hline $\begin{array}{l}\text { Tested nominal wall } \\
\text { thickness }\end{array}$ & $\sim 25 \mathrm{~mm}$ & $\sim 17 \mathrm{~mm}$ & $\sim 18 \mathrm{~mm}$ \\
\hline Test pipe length (mm) & 1710 & 1260 & 1580 \\
\hline Pipe installation year & \multicolumn{3}{|c|}{1922} \\
\hline Corrosion condition & $\begin{array}{l}\text { Pitting corrosion } \\
\text { internal surfaces at varying depths. Numerous pits in excess of } 5 \mathrm{~mm} \\
\text { were measured on the external surface of the pipe. }\end{array}$ \\
\hline Pipe material & \multicolumn{3}{|c|}{ CI, vertically pit cast } \\
\hline Corrosion patch information & $\begin{array}{c}\text { elliptical with flat } \\
\text { base }\end{array}$ & elliptical \\
\hline $\begin{array}{l}\text { Shape of the patch } \\
\text { circular }\end{array}$ & $\sim 400 \mathrm{~mm}$ \\
\hline $\begin{array}{l}\text { length (longitudinal } \\
\text { direction) of patch }\end{array}$ & $\sim 200 \mathrm{~mm}$ & $\sim 330 \mathrm{~mm}$ & $\sim 160 \mathrm{~mm}$ \\
\hline $\begin{array}{l}\text { width } \\
\text { (circumferential } \\
\text { direction) of patch }\end{array}$ & $\sim 200 \mathrm{~mm}$ & $\sim 100 \mathrm{~mm}$ & $\sim 40$ and \\
\hline
\end{tabular}




\begin{tabular}{|l|l|l|l|}
\hline $\begin{array}{l}\text { Remaining wall } \\
\text { thickness at patch }\end{array}$ & $\sim 5 \mathrm{~mm}$ (curved) & $\sim 4 \mathrm{~mm}$ (uniform) & $\sim 3.5 \mathrm{~mm}$ (curved) \\
\hline
\end{tabular}

\subsection{Determination of model parameters and assumed failure criterion for CI pipe}

The parameters for the hyperbolic nonlinear model (MHM-CI) were determined through a series of standard uniaxial tensile and compressive tests, according to the Standard [16]. All these tested coupons were cut out from the same decommissioned CI pipeline in Sydney, close to the section where the three tested pipe specimens were collected. The measured stress-strain relationships are plotted in Figure 2, where some variations of the nonlinear stress-strain responses indicate the natural variation of the cast iron due to the manufacturing process. Since the measured stress-strain relationships do not show substantial variations in pipe strength, e.g., less than $10 \%$ or so, an approximate averaged stress-strain relationship (represented by the Uni_1 tensile and compressive result marked with bold black lines) was selected for calibrating parameters used in the hyperbolic nonlinear elastic model, i.e., MHM-CI. The calibrated model parameters, together with the pipe density and the measured typical Poisson's ratio for finite element modelling are all listed in Table 2. These parameters were considered to be identical for all three pipe burst tests in the remainder sections, assuming that the material heterogeneity of cast iron in the three pipe specimen that were collected from the same pipeline does not vary significantly.

In addition, the yield (tensile) stress for all pipes was assumed to be the same, being around $103 \mathrm{MPa}$ as observed from the Uni_1 tensile test result in Figure 2(a). Considering that (brittle) CI material fails as a result of maximum principal tensile stress occurrence, our stress failure criterion assumes that local leak (or yield) failure initiates when the maximum principal tensile stress at the corroded patches is equal to the ultimate tensile strength of 103 MPa. Furthermore, the authors propose that when the failure length grows to be a certain value that can be determined using fracture mechanics (detailed later in section 4.2.3), the modelled pipe is considered to burst through a major break involving one large or multiple cracks. 


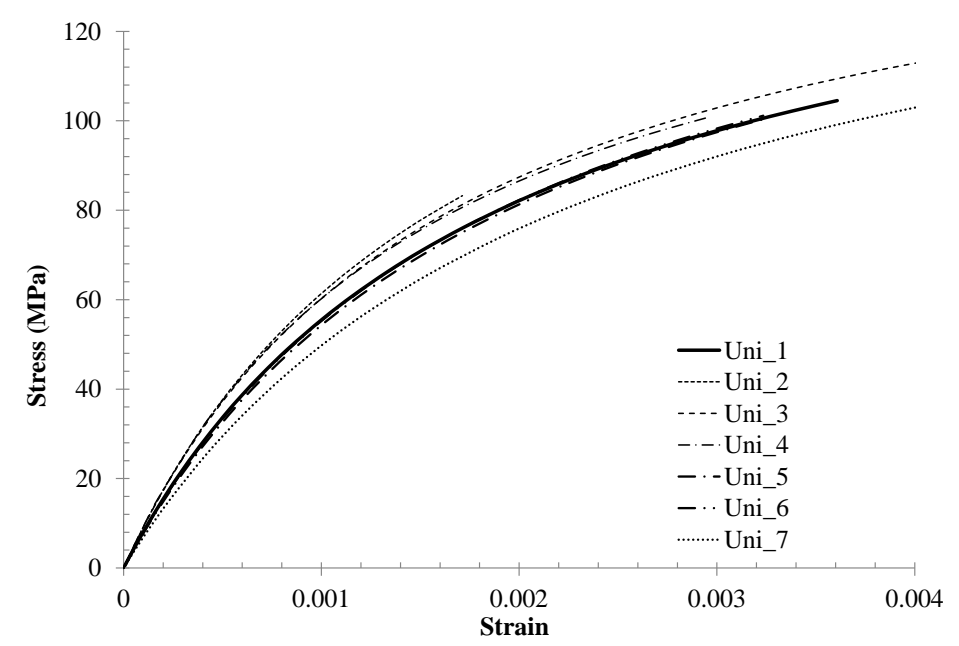

(a) Uniaxial tensile test

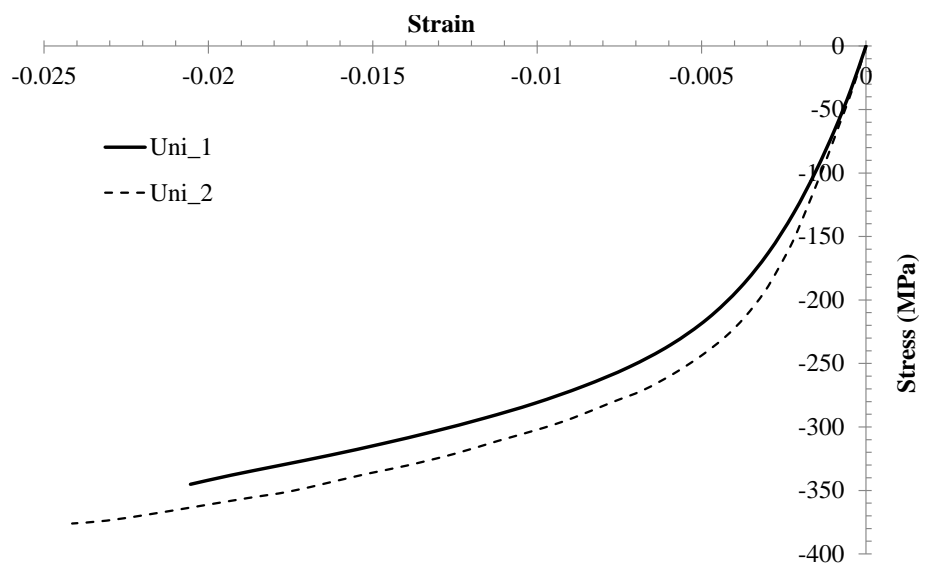

(b) Uniaxial compressive test

Figure 2. Uniaxial tensile and compressive test results

Table 2 Calibrated parameters for hyperbolic model (MHM-CI) for pipe testing

\begin{tabular}{|c|c|c|c|c|c|c|}
\hline \multirow{3}{*}{$\begin{array}{l}\text { Sample } \\
\text { All three }\end{array}$} & \multirow{2}{*}{$\begin{array}{l}\text { Density } \\
\left(\mathrm{kg} / \mathrm{m}^{3}\right)\end{array}$} & \multirow{2}{*}{$\begin{array}{c}\text { Poisson's } \\
\text { ratio }\end{array}$} & \multicolumn{4}{|c|}{ Mechanical parameters for hyperbolic nonlinear model } \\
\hline & & & \multicolumn{2}{|c|}{$\begin{array}{l}\text { If max principal stress in } \\
\text { tension }(+\mathrm{ve})\end{array}$} & \multicolumn{2}{|c|}{$\begin{array}{l}\text { If max principal stress in } \\
\text { compression (-ve) }\end{array}$} \\
\hline & & & $\alpha_{T}\left(\mathrm{MPa}^{-1}\right)$ & $\beta_{T}\left(\mathrm{MPa}^{-1}\right)$ & $\alpha_{C} \quad\left(\mathrm{MPa}^{-1}\right)$ & $\beta_{C}\left(\mathrm{MPa}^{-1}\right)$ \\
\hline pipe & 7850 & 0.23 & & & & \\
\hline specimen & & & $1.17 \mathrm{e}-5$ & 0.0063 & $1.13 \mathrm{e}-05$ & -0.0024 \\
\hline
\end{tabular}




\section{Numerical simulations of pipe tests}

\subsection{Finite element modelling}

FEAs using ABAQUS [17] were configured to model pipe burst tests 1, 2 and 3 subject to monotonically increased water pressure. As the pitting corrosion on the pipes appeared to be extremely irregular (as seen in Figures 1(d) to 1(f)), a large amount of fine elements were required to properly discretise the modelled pipes. As a result, a total of 2694062, 1519878 and 2152904 ten-node quadratic tetrahedral elements were used to properly discretise the modelled pipes 1, 2 and 3, respectively. The use of quadratic ( $2^{\text {nd }}$ order) elements can produce more accurate stresses than the use of $1^{\text {st }}$ order elements, while the computational time between the $1^{\text {st }}$ and $2^{\text {nd }}$ order may not be significantly different, as the constitutive model MHM-CI is a nonlinear elastic rather than an elastoplastic model. As a result, the running time for the three pipes with such a large number of elements is about $12 \mathrm{hrs,} \mathrm{thanks}$ to the function of parallel execution with 20 cores.

All three modelled pipes were fixed at the top and bottom surfaces to approximate the actual testing procedure, and the linearly increasing water pressure acting on each pipe specimen was modelled via applying internal pressure on the pipe internal surface. Self-weight of each pipe was also considered throughout the analysis, although this is of minimum influence on pipe mechanical performance. The same series of parameters of the hyperbolic nonlinear elastic model (MHM-CI) shown in Table 2 were used to characterize the nonlinear material behaviour of the cast iron of the three modelled pipes.

\subsection{Numerical results and analyses}

\subsubsection{Stress distribution}

It is understood that the stresses on a pressurized corroded CI pipe may be distributed in a very irregular way, heavily depending on the locations of pitting corrosion. Using our numerical simulations, the scattered distributed stresses like the maximum tensile stresses, can be shown in great detail, for example, in Figures 3 to 5 when an (gauss) integration point 
of the element at the middle of the machined corroded patch just started to yield. Note that the legend and contour of the stress do not represent the stress of an integration point but an averaged stress of a node. The averaged nodal stress is the average of all connected element stress values to that node, and each element stress is calculated from the extrapolations of the stresses at the integration points for that element out to the element nodes. Therefore, the maximum stress in the legend looks slightly more than the tensile strength of $103 \mathrm{MPa}$, which actually indicates the stress of a surrounding integration point just reaching the yield stress of $103 \mathrm{MPa}$.

The obtained numerical results of the three pressurized pipes show that the stresses are quite scattered with some local areas under significant tension while their vicinities under minor tension, depending on the severity of pitting corrosion on the pipes. The relativly deep corrosion areas like the machined corrosion patches, where the most significant tensile stresses are conentrated, are apparently the most critical areas when estimating the likelihood of pipe leaks and bursts. These complicated stress distributions due to pitting corrosion are completely different from that on the pipe with a (or reduced) uniform wall thickness. The latter approach using a reduced uniform wall thickness is a common treatment that has been widely adopted in practice and literature in the analysis of corroded pipes [5-7]. From our demonstrations in Figures 3 to 5, it is clear that the idealization of the corroded pipes using a (reduced) uniform wall thickness may lead to a significantly inaccurate stress estimate of a corroded pipe, particularly when the pipe is severely corroded. If assuming a reduced uniform wall thickness and without the consideration of stress concetration due to surface defects, the tensile stress of a pipe could be quickly estimated either by the geniune equation $\sigma_{\text {uniform }}=P R_{\text {inner }} / T_{\text {reduced uniform }}$, or a uniform finite element pipe model that could be quickly resolved within several hours. However, the obtained tensile stress may be largely low estimated. Taking the pipe 1 as an example, where considering $T_{\text {reduced uniform }}=20 \mathrm{~mm}$ (original wall thickness of $25 \mathrm{~mm}$ minus the remaining wall thickness of $5 \mathrm{~mm}), R_{\text {inner }}=(660$ $\mathrm{mm}-2 \times 25 \mathrm{~mm}) / 2=305 \mathrm{~mm}$, and under the water pressure $P=3 \mathrm{MPa}$, the resulted $\sigma_{\text {uniform }}=45$ $\mathrm{MPa}$, which is far below the tensile strength of $103 \mathrm{MPa}$. As a comparison, if the corroded 
surface is well captured as shown in Figure 3, the calculated tensile stress at the centre of the corroded patch already reaches the tensile strength, causing local yield.

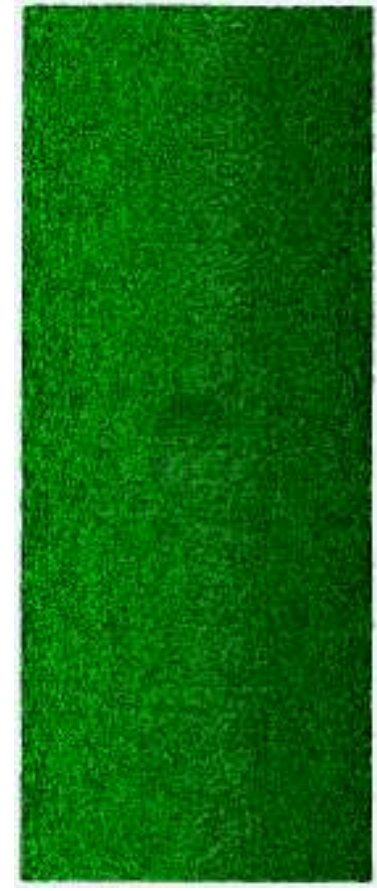

(a)

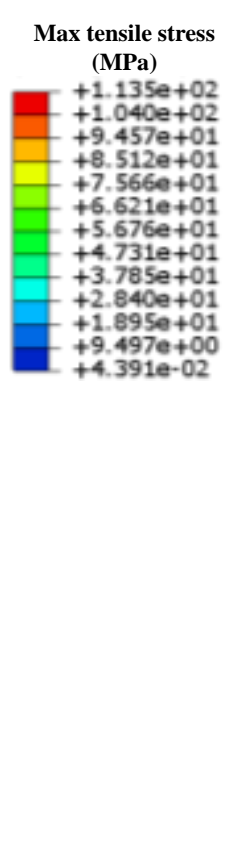

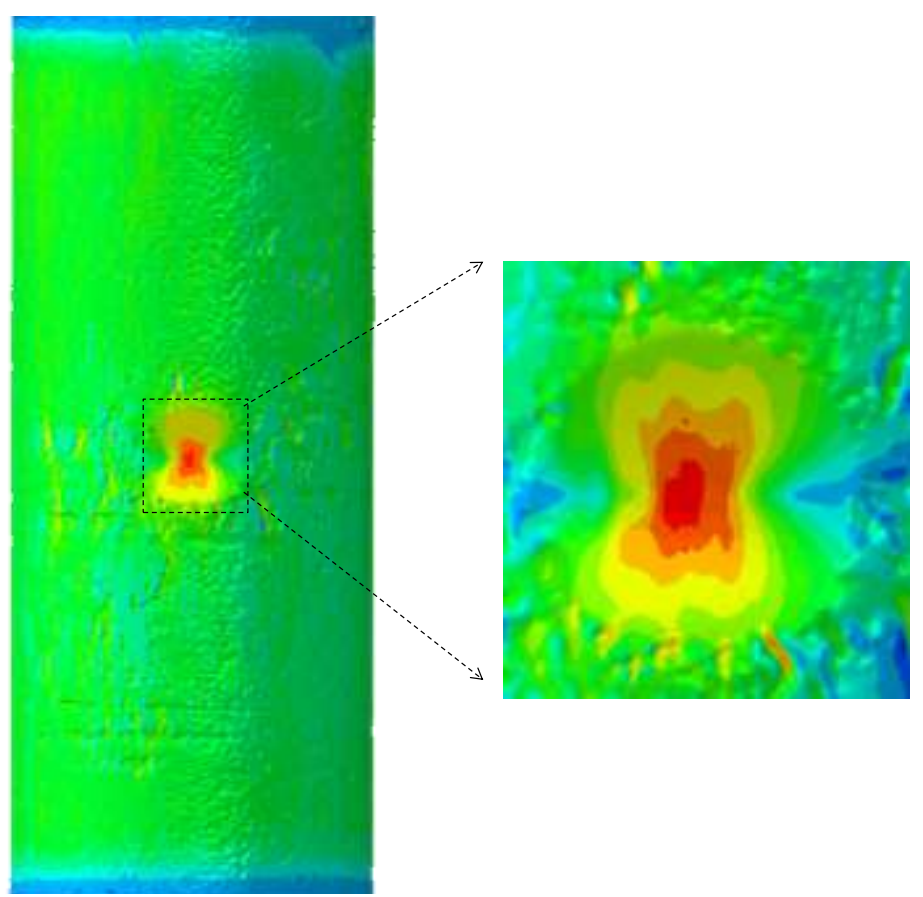

(b)

(c)

Figure 3. Finite element model of pipe burst test 1: (a) mesh configuration of the pipe; (b) finite element model shows maximum tensile stress distribution when the middle of the artificial circular corroded patch started to yield and leak, and (c) zoomed stress contour for the circular corroded patch 


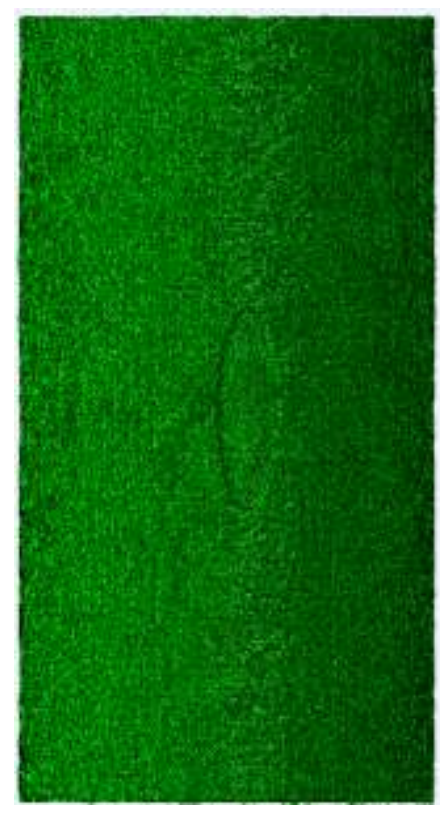

(a)

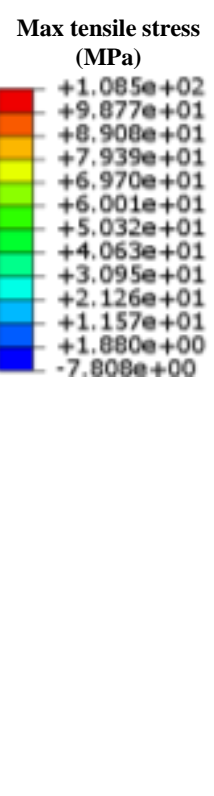

(b)

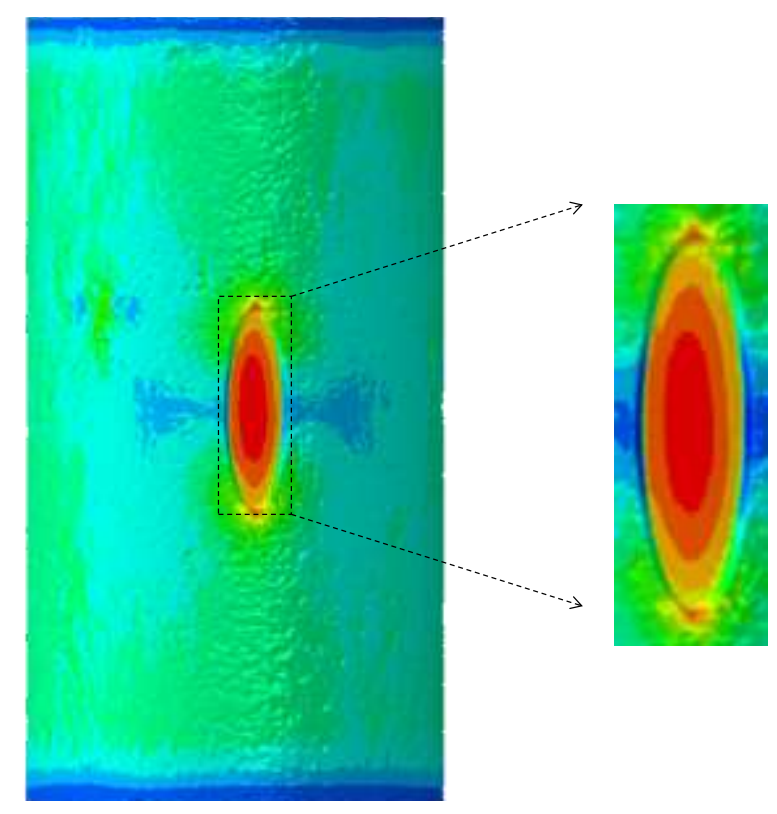

(c)

Figure 4. Finite element model of pipe burst test 2 (a) mesh configuration of the pipe; (b) finite element model shows maximum tensile stress distribution when the middle of the artificial elliptical corroded patch started to yield and leak, and (c) zoomed stress contour for the elliptical corroded patch 


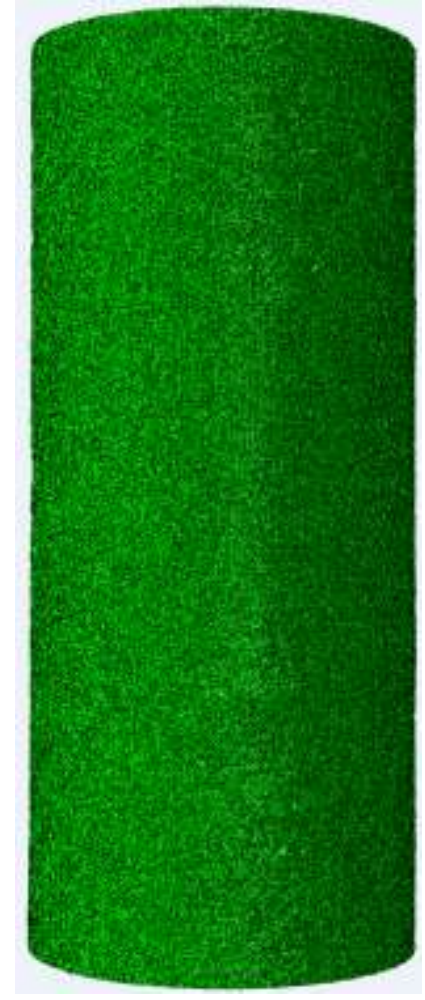

(a)

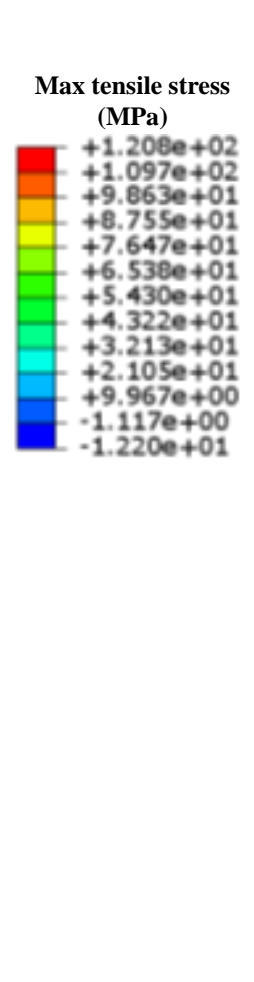

Figure 5. Finite element model of pipe burst test 3 (a) mesh configuration of the pipe; (b) finite element model shows maximum tensile stress distribution when the middle of the artificial elliptical corroded patch started to yield and leak, and (c) zoomed stress contour for the elliptical corroded patch

\subsubsection{Hoop strains}

Data obtained from the pipe tests indicated that the increasing water pressure would result in significant hoop strains on the machined patches; the maximum strains occurred at the centre of the machined patches, and then the strains gradually decreased with further distance down to the edge of the patches. As shown in Figure 6, two or three measurement points were used in the three tests. Figure 6 also shows comparisons of the measured and numerical water pressure and hoop strain relationships. The hoop strains of the three pipes were obtained using FEAs and the MHM-CI, a hyperbolic nonlinear elastic model developed by the authors. Despite the differences in the exact quantitative behaviour between the measured and predicted results, general agreement can be observed of the behaviour pattern where the 
highest hoop strains occurs at the centre of the patch and the hoop strain gradually decreases away from the centre.

It can be seen that the best prediction of the hoop strains was obtained for pipe test 3 , in comparison to the other two pipe tests. This finding may indicate that the averaged hyperbolic model parameters in Table 2 may be most suitable to produce the overall mechanical response of the pipe 3 . In addition, the prediction of hoop strains on pipes 1 and 2 can be improved by slightly adjusting the model parameters, e.g., using a reduced elastic modulus (corresponding to a higher $\alpha$ from Eq. (2)), in order to achieve better fits, although not shown here.

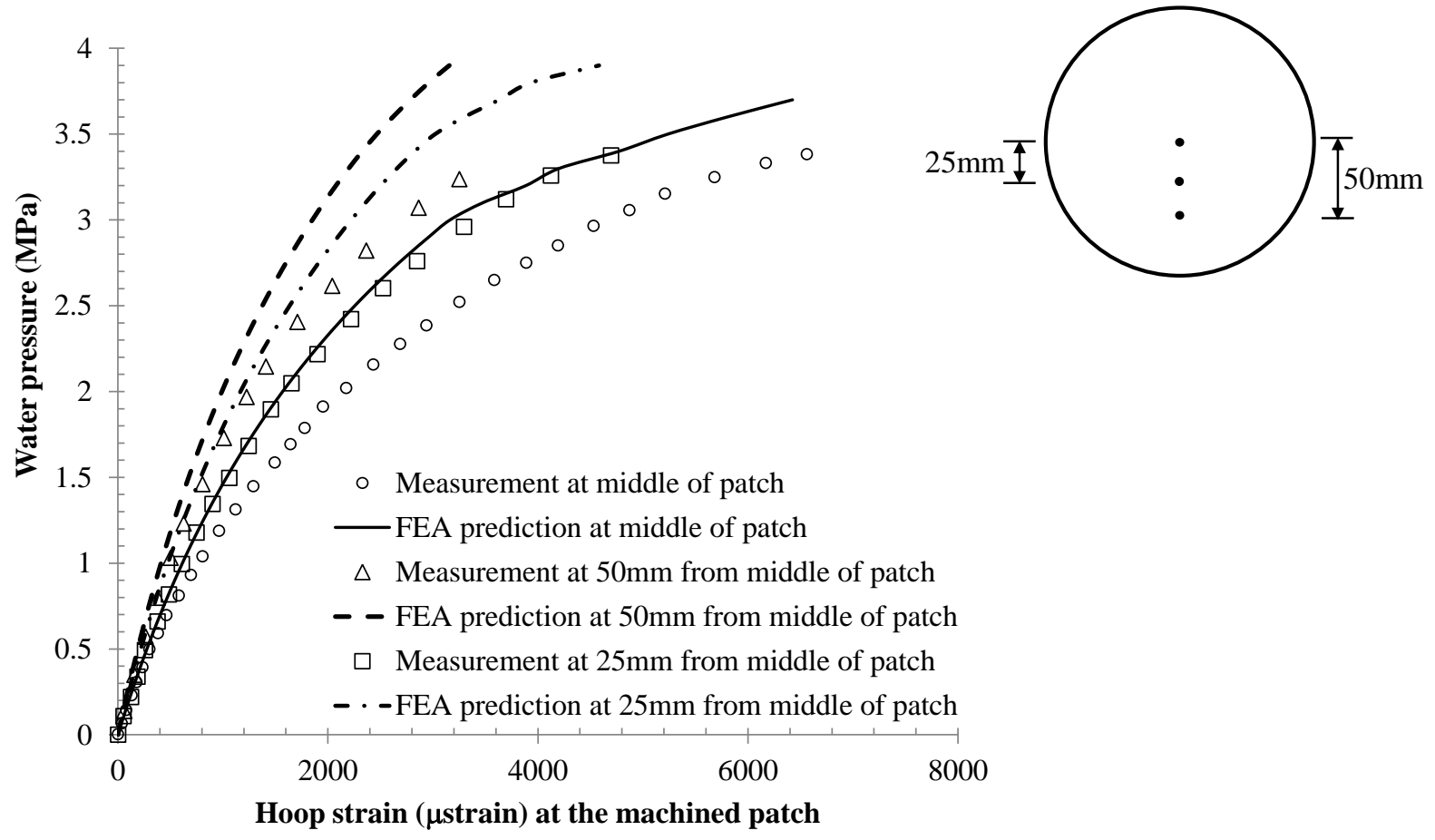

(a) Pipe test 1 

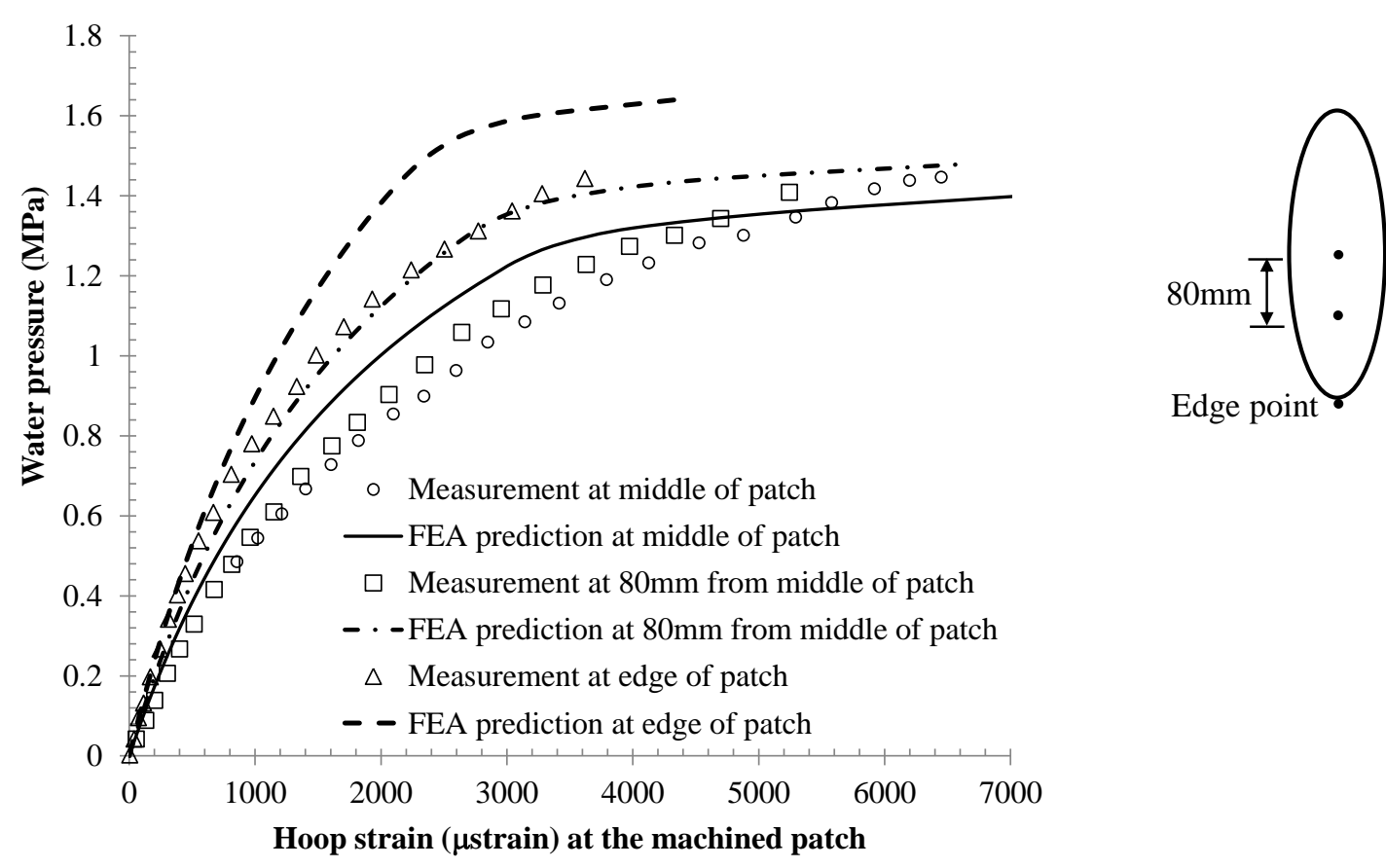

(b) Pipe test 2
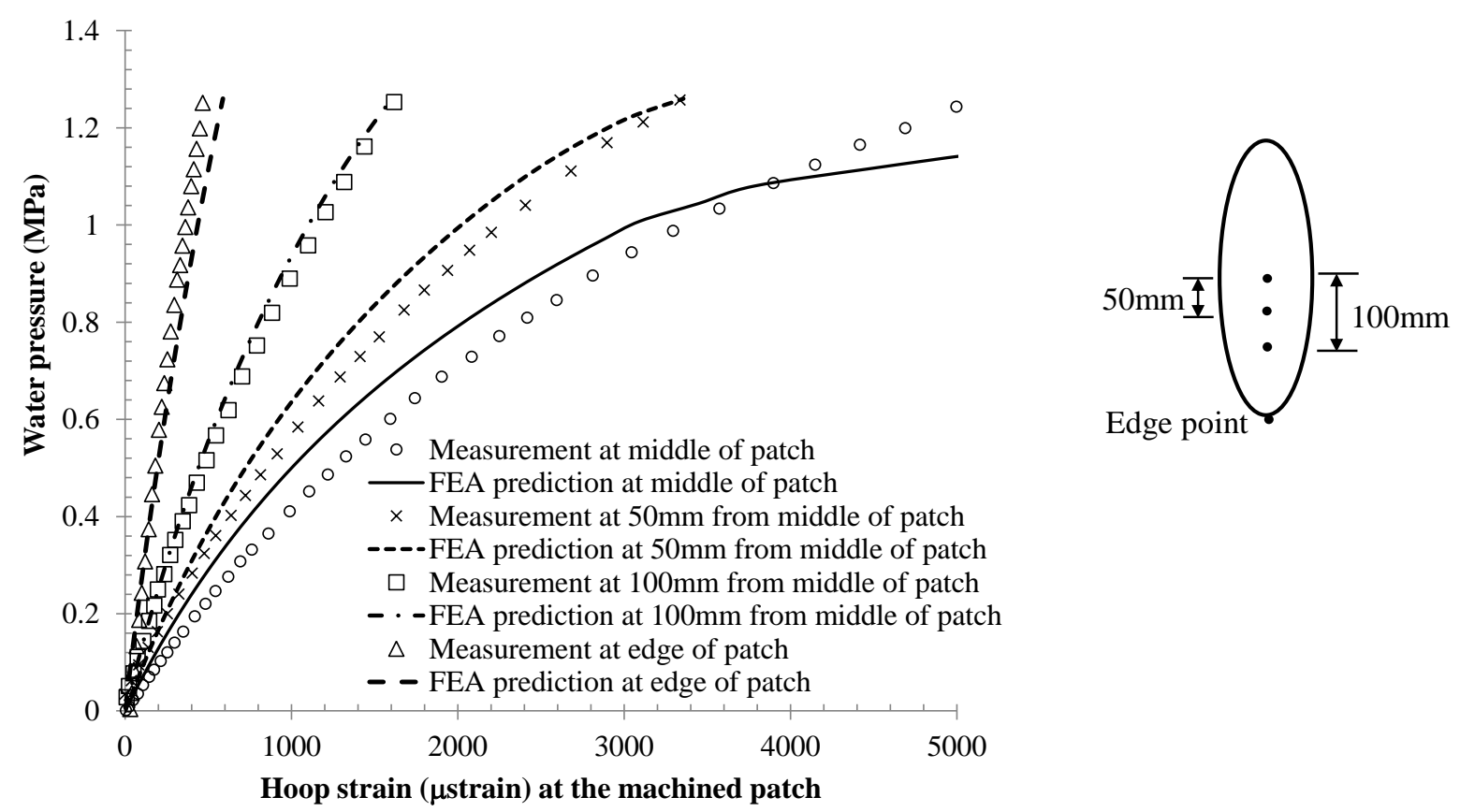

(c) Pipe test 3

Figure 6. Hoop strain comparisons between FEAs and pipe test measurements

\subsubsection{Leak and burst pressures}

Estimating remaining life of a corroded CI pipe is a challenge facing water utilities, as all current underground CI pipelines have ages around 50 to 150 years and undergone 
predominantly variable pitting corrosion. One of the key issues is to investigate the size of a corrosion patch that may cause a pipe failure, starting from leakage and then to burst, which are mainly driven by soil movement and/or water pressure. The water pressures to cause pipe yield can be predicted using our FEAs. As shown in Figures 3(a) to 3(c), the water pressures corresponding to starting of crack (with possible leakage) at the centre of the machined patches of pipes 1, 2 and 3, are approximately $3000 \mathrm{kPa}, 1240 \mathrm{kPa}$ and $970 \mathrm{kPa}$, respectively. Comparatively, the measured water pressures at first leakage of the three pipes are approximately $3200 \mathrm{kPa}, 1290 \mathrm{kPa}$ and $800 \mathrm{kPa}$, indicating prediction errors of $6.25 \%, 3.86 \%$ and $21.25 \%$, respectively for pipe tests 1,2 and 3 . These errors may arise from a number of factors including the applicability of the model parameters, model itself and any other internal defects that cast iron may have in its microstructure. Unfortunately, however, such internal defects cannot be detected and scanned by the current laser scanning technique.

Once a crack is initiated, for the next phase of pressuring up to a burst, fracture mechanics theory is used to determine the critical crack length that would generate a fast fracture across the rest of the corroded as well as the uncorroded section of the pipe. This is appropriate since as seen in the experiments, a sharp crack is likely to be generated during initial failure leading to leakage. In fracture mechanics, the fracture is dependent on fracture intensity $K_{i}$ that can be expressed as [18]:

$$
K_{i}= \begin{cases}\sigma \sqrt{\pi a}\left(1+1.25 \lambda^{2}\right)^{0.5} & \text { if } 0<\lambda \leq 1 \\ 0.6+0.9 \lambda & \text { if } 1<\lambda \leq 5\end{cases}
$$

where

$$
\lambda=a \sqrt{R t}
$$

$$
\sigma=\frac{P R}{t}
$$


In the above Equations $3-5, R$ is the radius of a pipe and $t$ indicates the wall thickness of the pipe; $P$ means the water pressure; $a$ denotes a half length of a crack along the pile length (axial or longitudinal) direction.

The critical fracture intensity factor, i.e., the fracture toughness, of cast iron is typically in the range from 5 to $20 \mathrm{MPa} \mathrm{m}^{0.5}$ [19-22]. Our recent fracture tests of the cast iron pipe specimen showed the intensity factor was approximate $12 \sim 17 \mathrm{MPa} \mathrm{m}^{0.5}$. Therefore, a relatively high value of 15 was adopted for simplicity in our study; then the critical crack length, at which the pipe bursts can be determined for a given water pressure $P$.

As shown in Figures 7 (a) to 7 (c), the fracture mechanics theory results (open red circles) show the reduction of the critical length required to cause fast fracture with increasing water pressure. On the other hand, the FEA results (dark black circles) show the crack (yield) length growing with increasing water pressure. As a practical and simple explanation, when both the current crack length and critical crack length curves intersect, a burst is expected to occur. A more detailed analysis would involve the modelling of crack growth as the pressure is increased. As can be seen in Figures 7 (a) to 7 (c), the numerically estimated burst pressures are approximately 3550, 1300 and $1310 \mathrm{kPa}$, respectively, for pipes 1, 2 and 3 . Experimentally only one burst pressure was available and that is for pipe test 2, for which the measured burst pressure was approximately $1440 \mathrm{kPa}$. This value is reasonably close to the predicted $1300 \mathrm{kPa}$. However, due to the pressure limit of the equipment used in the burst testing, the burst pressures of pipe testing 1 is not available for comparison. Nevertheless, the maximum recorded water pressure of $3700 \mathrm{kPa}$ did not break pipe 1, which indicates that the burst pressure of pipe 1 must be over $3700 \mathrm{kPa}$. Pipe 3 was intentionally left unbroken, as it was to be used for fatigue testing, and therefore, the burst pressure of pipe 3 was not available.

Table 3 summarises all leak and burst pressures of the three pipes obtained from testing and numerical predictions. Under field conditions, when corrosion has progressed sufficinetly, a first crack may occur which could lead to lekage if the crack is large enough and the cement 
lining (if any) would get cracked as well. It should be noted that if the cast iron can get cracked then it is most likely that cement lining would get cracked too, since the failure strain of cast iron is typically 4000 to 7000 microstrains whereas that of cement lining is typically around 200 microstrains [23]. Subsquent crack growth with predominantly pressure cycling (i.e., transient pressure events in the network) will be subcrtical until the critical length is reached for spontaneous crack growth casuing a major burst. This time window referred to as 'Leak Before Break Window' is of practical vlaue for utilities to intervent prior to a burst. Hence, more research is needed to chracterise this window of time.

Table 3 Approximate values of measured and predicted leak and burst water presures

Pipe burst test Leak pressure (kPa)

Burst pressure (kPa)

Measured Predicted Measured Predicted

\begin{tabular}{lllll}
\hline Pipe 1 & $\sim 3200$ & $\sim 3000$ & N/A & $\sim 3550$ \\
Pipe 2 & $\sim 1290$ & $\sim 1240$ & $\sim 1440$ & $\sim 1300$ \\
Pipe 3 & $\sim 800$ & $\sim 970$ & N/A $^{2}$ & $\sim 1310$
\end{tabular}

Note 1: exact burst pressure is not available as the single small volume pump used in the test was not sufficiently powerful enough to produce high pressure when water leaked quickly. As a result, the maximum recorded water pressure is $3700 \mathrm{kPa}$, at which the pipe burst had not yet occured.

Note 2: the pipe was intentionally left unbroken for subsequent fatigue tests. 


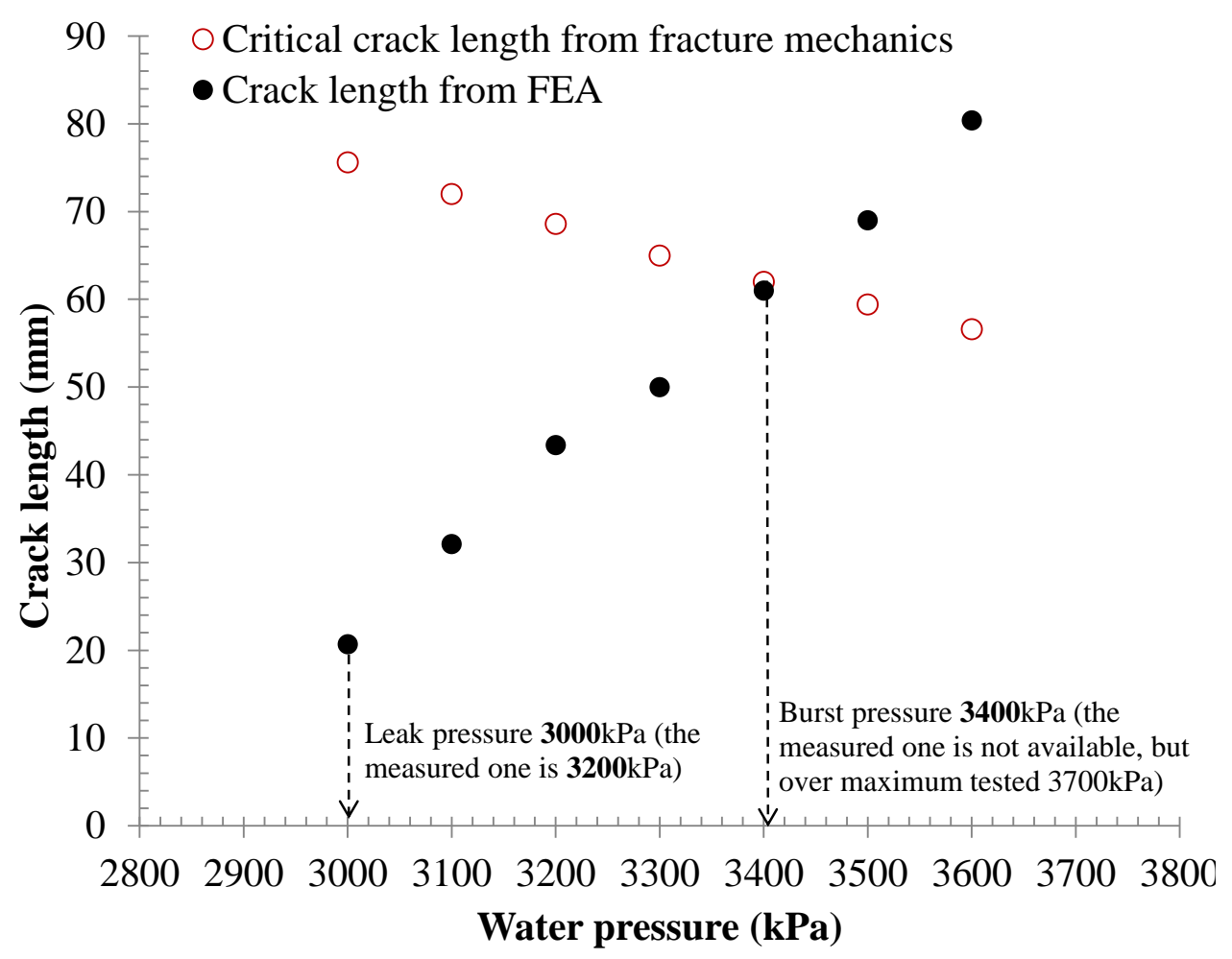

(a) Pipe test 1

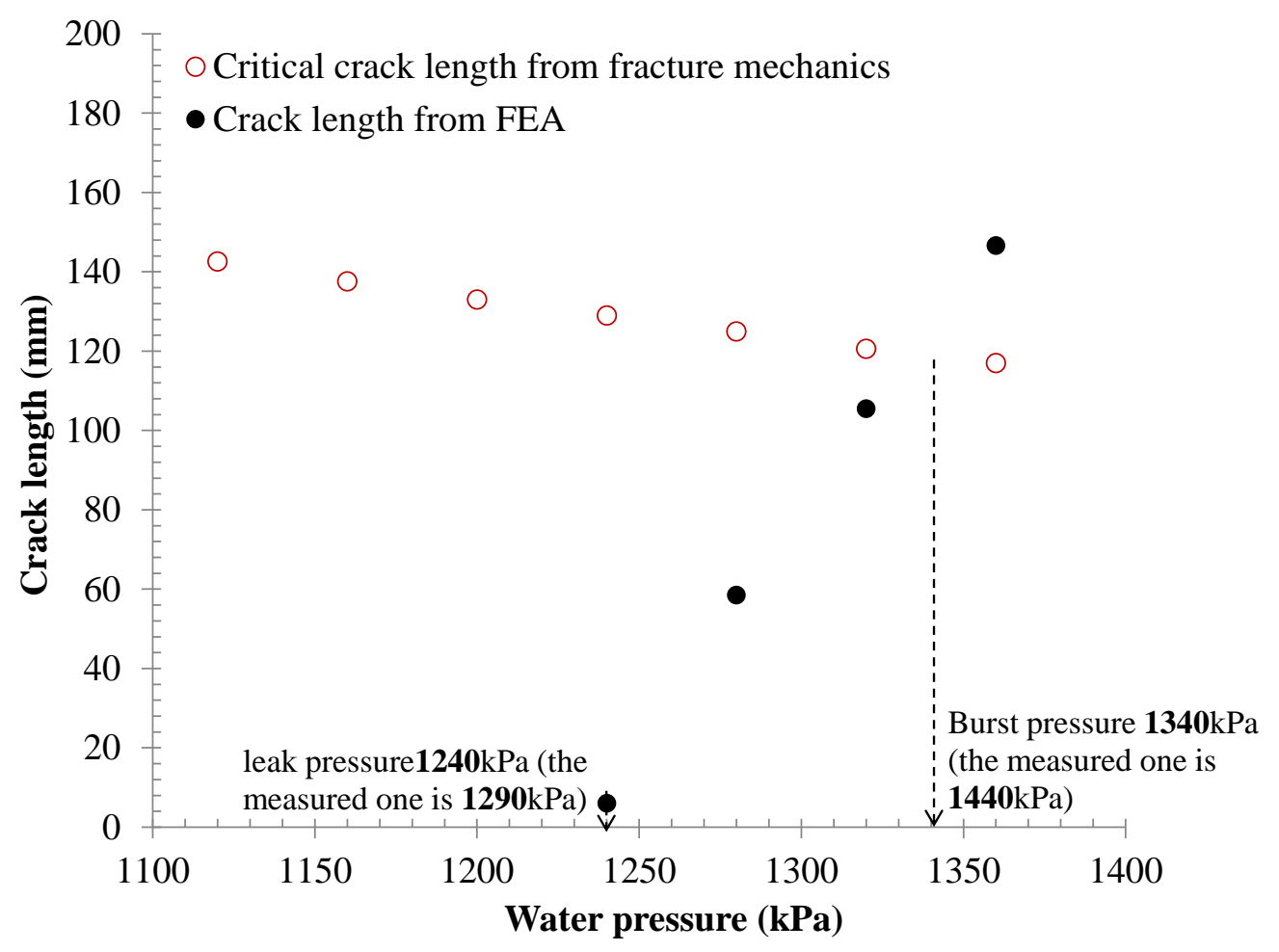

(b) Pipe test 2 


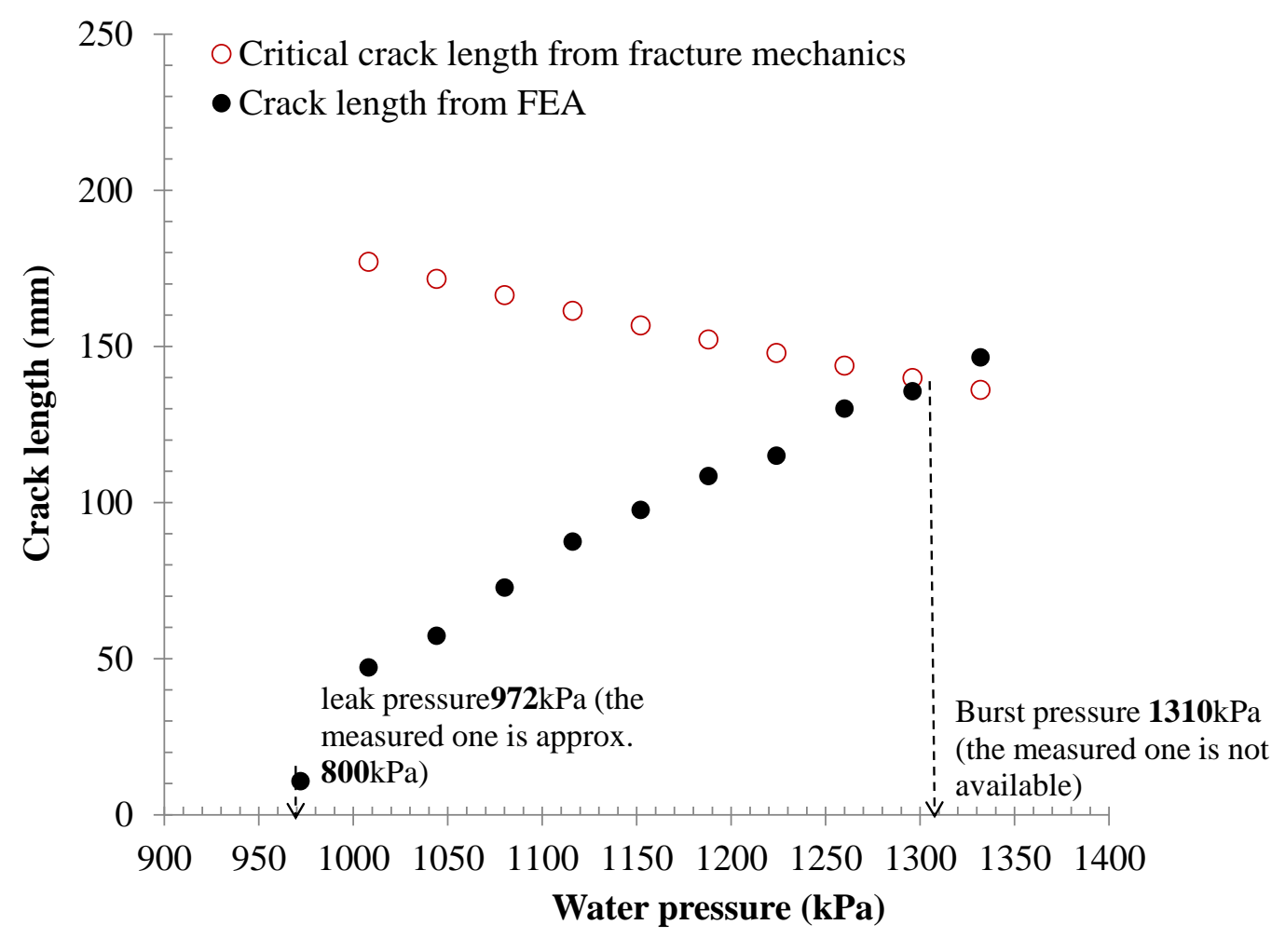

(c) Pipe test 3

Figure 7. Development of crack length with increasing water pressure for all pipe simulations

Our current study demonstrates the phenomenon of the leak before break for brittle cast iron pipes. This is to address that even the brittle material like a cast iron, a leaked pipe may still have chances to survive for some period till it totally bursts. However, the determination of the length of the window of leak before break is not straightforward. It requires fracture growth simulations under cyclic loading most likely in low cycle fatigue. This is another area of research that we are currently progressing but would require a substantial research effort. Our current approach is a practical and simplified approach to a complex problem fulfilling an industry need for remaining life estimations.

\section{Conclusions}

Finite element analysis was developed to study the structural capacities of three pressurized corroded cast iron (CI) pipes. The approach relies on two aspects: 1) a simple hyperbolic 
nonlinear elastic constitutive law (MHM-CI) that takes into account the inherent nonlinearity of cast iron; and 2) appropriate finite element discretization of surface corrosion pits of CI pipes. The surface corrosion pits were obtained through a high-resolution laser-scanning technique. The suitability of the proposed approach was demonstrated through its application to predict maximum tensile stresses, hoop strains, leak and burst pressures of the modelled pipes. Many of these numerical predictions were validated by corresponding pipe testing results, which have been recently carried out in the Monash Civil Engineering laboratory by the authors. The numerical findings establish the basis for using the proposed numerical analyses for stress analyses and failure assessments of deteriorated corroded CI pipes relatively cheaply in comparison to undertaking expensive burst testing.

With the proposed FEA approach, water utilities may be able to evaluate the remaining structural capacity of a corroded and aged CI pipe with more confidence. Additionally, the authors have developed an efficient statistically predictive model to approximate numerical solutions [24] and conducted probabilistic analysis based on FEA solutions [25]. Besides, a closed-form stress analysis solution close to numerical calculations of concentrated stresses due to corrosion is also being under developed. Such a solution along with the fracture mechanics solution given here could provide a quick estimate for the pressures applicable to leaks and bursts.

None the less, more research is needed as follows: 1) to improve the model's capability to capture the impact of cyclic loads, as insitu pipes are generally subject to repeated episodes of loading and unloading due to pressure surges and environmental changes; 2) to quantify properly the time of the "Leak before Break Window", which needs to analyse the frequency of internal and external loadings.

\section{Acknowledgements}

This publication is an outcome of the "Advanced Condition Assessment \& Pipeline Failure Prediction Project" funded by Sydney Water Corporation, Water Research Foundation, Denver, USA, Melbourne Water, Water Corporation (WA), UK Water Industry Research 
Ltd., South Australia Water Corporation, South East Water, Hunter Water Corporation, City West Water, Queensland Urban Utilities, Monash University, the University of Technology Sydney and the University of Newcastle. The research partners are Monash University (lead), the University of Technology Sydney, and the University of Newcastle. Financial support from National Science Foundation of China (Grant No. 51609072) is also acknowledged.

\section{References}

1. Schlick, W.J., Moore, B.A. Strength and elastic properties of cast iron in tension, compression, flexure, and combined tension and flexure. Vol. Bulletin 127. Iowa State College of Agriculture and Mechanic Arts. 1936.

2. Vitanage, D.C., Kodikara, J., Allen, G. Collaborative research on condition assessment and pipe failure prediction for critical water mains. Water Asset Manage. Int 2014; 10(3): 15-18.

3. Lim, K., Wong, L., Chiu, W.K., Kodikara, J. Distributed fiber optic sensors for monitoring pressure and stiffness changes in out - of - round pipes. Structural Control and Health Monitoring 2016; 23(2): 303-314.

4. Rajeev, P., Kodikara, J., Robert, D., Zeman, P., Rajani, B. Factors contributing to large diameter water pipe failure. Water Asset Management International 2014; 10(3): 9-14.

5. Hebor, M., Ricles, J. Residual Strength and Repair of Corroded Marine Tubulars. National Center for Engineering Research on Advanced Technology for Large Structural Systems, Report 1994(94-10).

6. Rajani, B. Nonlinear stress-strain characterization of cast iron used to manufacture pipes for water supply. Journal of Engineering Materials and Technology 2012; 134(4): 1-8.

7. Seica, M.V., Packer, J.A. Simplified numerical method to evaluate the mechanical strength of cast iron water pipes. Journal of infrastructure systems 2006; 12(1): 60-67.

8. Rajeev, P., Kodikara, J. Numerical analysis of an experimental pipe buried in swelling soil. Computers and Geotechnics 2011; 38(7): 897-904.

9. Sakakibara, N., Kyriakides, S., Corona, E. Collapse of partially corroded or worn pipe under external pressure. International Journal of Mechanical Sciences 2008; 50(12): 1586-1597. 
10. Seica, M., Packer, J. Mechanical Properties and Strength of Aged Cast Iron Water Pipes. Journal of Materials in Civil Engineering 2004; 16(1): 69-77.

11. Mao, J., Bao, S. Comparative studies on buckling behaviors of $\mathrm{T}$ joint and pipe by varying geometric parameters and analysis methods. International Journal of Mechanical Sciences 2015; 90: 113-121.

12. Liu, Y., Cen, Z., Chen, H., Xu, B. Plastic collapse analysis of defective pipelines under multi-loading systems. International Journal of Mechanical Sciences 2000; 42(8): 1607-1622.

13. Harris, C.W., Response of jointed cast iron pipelines to parallel trench construction, in Report to New York Gas Group, Report No. 83-5. 1983, Cornell University, May.

14. Kondner, R.L. Hyperbolic stress-strain response: cohesive soils. Journal of the Soil Mechanics and Foundations Division 1963; 89(1): 115-144.

15. Zhang, C., Ji, J., Kodikara, J., Rajani, B. Hyperbolic constitutive model to study cast iron pipes in 3-D nonlinear finite element analyses. Engineering Failure Analysis 2017; 75: 26-36.

16. International, A., Designation: E8M-04 in standard test methods for tension testing of matallic materials. 2004, ASTM International: PA, USA. p. 1-24.

17. ABAQUS. ABAQUS/Explicit User's Manual, Version 6.12. Providence, RI: Hibbitt, Karlsson \& Sorensen. 2012.

18. Piley, W., Peterson's stress concentration factors. 1997, John Wiley \& Sons Inc., USA.

19. Makar, J., Rajani, B. Gray cast-iron water pipe metallurgy. Journal of Materials in Civil Engineering 2000; 12(3): 245-253.

20. Rajani, B., Makar, J., McDonald, S., Zhan, C., Kuraoka, S., Jen, C.-K., Viens, M., Investigation of grey cast iron water mains to develop a methodology for estimating sevice life. 2000: Ottawa, Canada.

21. Li, C.Q., Yang, S.T. Stress intensity factors for high aspect ratio semi-elliptical internal surface cracks in pipes. International Journal of Pressure Vessels and Piping 2012; 96-97: 13-23.

22. Li, C.-Q., Fu, G., Yang, W. Stress intensity factors for inclined external surface cracks in pressurised pipes. Engineering Fracture Mechanics 2016; 165: 72-86. 
23. Robert, D., Jiang, R., Rajeev, P., Kodikara, J. Contribution to cement mortar lining to the structural capacity of cast iron water mains. ACI Materials Journal 2016; 113(03): 295-306.

24. Ji, J., Zhang, C., Kodikara, J., Yang, S.-Q. Prediction of stress concentration factor of corrosion pits on buried pipes by least squares support vector machine. Engineering Failure Analysis 2015; 55: 131-138.

25. Ji, J., Robert, D.J., Zhang, C., Zhang, D., Kodikara, J. Probabilistic physical modelling of corroded cast iron pipes for lifetime prediction. Structural Safety 2017; 64: $62-75$. 


\section{Graphical Abstract}
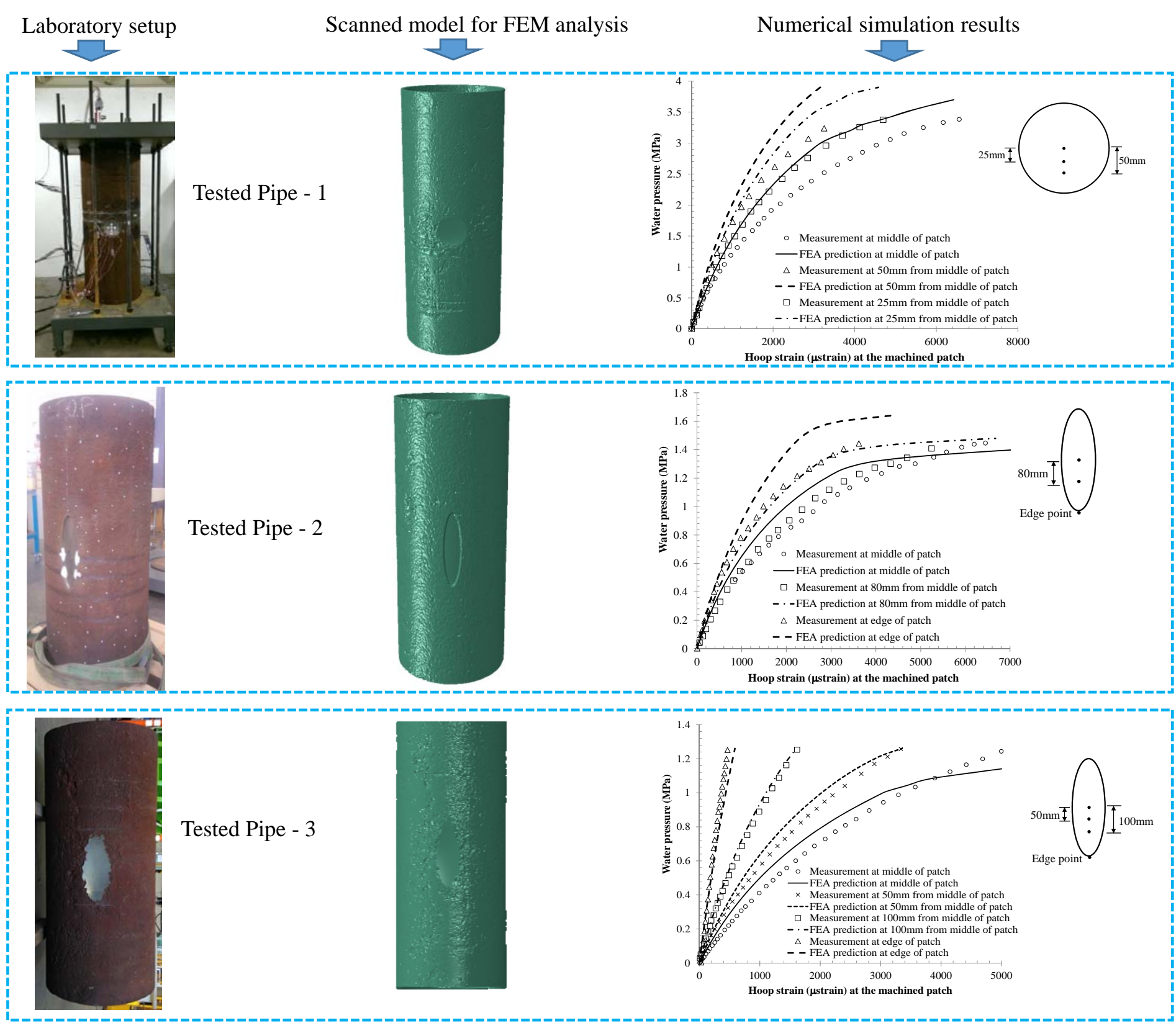